\title{
La epidemia del SIDA en el Perú.
}

\section{AIDS epidemic in Perú.}

\author{
Antigoni Juana'. \\ ${ }^{1}$ Dirección de Investigación Epidemiológica "Dr. Hugo Lumbreras Cruz" del Instituto \\ Nacional de Salud. \\ ${ }^{2}$ Instituto de Medicina Tropical "Alexander von Humboldt" de la Universidad Peruana \\ Cayetano Heredia.
}

De acuerdo a las cifras oficiales en el Perú hasta abril de 1993, se han registrado 800 casos de SIDA (estadio IV de la infección por el virus de inmuno deficiencia humana, VIH). El subregistro se calcula entre el $50 \%$ a $100 \%$ por lo que cree que en realidad debe haber unos 1500 casos de SIDA de los cuales el $80 \%$ se encuentra en Lima y Callao.

1500 casos parecen pocos si los comparamos con otras enfermedades prevalecientes en nuestro país como la tuberculosis, el cólera, etc., pero esta cifra es realmente alarmante si pensamos que por cada caso de SIDA debe haber 10 a 20 personas infectadas por el VIH lo que significa 15 a 30 mil infectados, los que en unos 5 a 10 años van a desarrollar el SIDA. Es decir, en el Perú ya tenemos una epidemia de infectados por el VIH ante los que la ciencia nos ofrece poco a nada para evitar que desarrollen la enfermedad.

El 70\% de los casos de SIDA se presentaron en personas entre los 20 y 39 años de edad, lo que indica que el grupo en mayor riesgo de infectarse con el VIH son los adolescentes y/o adultos jóvenes (pues el período de incubación de la enfermedad es de seis meses a 15 o más años), que son justamente los grupos que aún no tienen pareja estable. La poca o ninguna información sobre sexualidad unida a la alta rotación de parejas durante esta búsqueda de la pareja estable los expone al VIH y a otras enfermedades de transmisión sexual.

Las tendencias autoritarias no pedagógicas de nuestra sociedad ejercen una gran presión sobre jóvenes imponiéndoles patrones rígidos de conducta en donde el sexo es considerado tabú ("de eso no se debe hablar"). Por otro lado los medios de comunicación masiva les dan una visión del sexo como la felicidad al alcance de la mano. Es así como nuestros jóvenes se refugian en el temprano ejercicio de su sexualidad, empujados por la sociedad de consumo en donde el sexo es moda y la felicidad está en consumir sexo.

De esta forma se distorsiona el desarrollo de la sexualidad haciendo a los jóvenes fácil presa de las drogas y el alcohol. 
Hay una doble moral en la práctica de la sexualidad pues lo que está negado para la mujer (las relaciones pre-matrimoniales) le está permitido al hombre.

Los jóvenes piensan que el sexo es peligroso, por la posibilidad de un embarazo no deseado, pero que deben iniciarse temprano sexualmente; esta dualidad los hace involucrarse en una práctica de alto riesgo para SIDA como es el coito anal.

El riesgo de la infección por el VIH está aumentando en la mujer, pues se ha observado que mientras que en 1987 se reportó una mujer con SIDA por cada 15 hombres, en 1992 se registró una mujer por cada 9 hombres con SIDA. Esto probablemente se debe a que la mujer en nuestro país está menos informada que el hombre en relación al sexo, así mismo el machismo caracterizado en nuestra cultura determina que la mujer no pueda decidir ¿cómo? ¿Cuándo? ¿Ni en que condiciones? tener relaciones sexuales, "ellas ven la sexualidad como algo peligroso y violento".

El impacto socio-económico del SIDA, la llamada tercera epidemia, ya se está empezando a sentir, pues la frágil estructura de los servicios de salud está recibiendo una demanda cada vez mayor de atención de los seropositivos al VIH. La imposibilidad del Ministerio de Salud es brindar una atención gratuita (hasta el test de despistaje del VIH no es gratuita), está obligando a los infectados a buscar la forma de asegurarse en el Instituto Peruano de Seguridad Social IPSS, pues es el único medio de asegurar no sólo la atención de salud sino también el sepelio y la pensión de viudez y/u orfandad para sus seres queridos.

Este fenómeno se da también en otros países en donde los seguros sociales son los que enfrentan el mayor porcentaje del costo de esta enfermedad. En el Perú aproximadamente el $70 \%$ de los casos de SIDA han sido y vienen siendo atendidos por el IPSS; siendo esta la institución que desde que se inicia la epidemia en nuestro país ha brindado una mayor y mejor atención a los pacientes VIH/SIDA, pues su infraestructura y organización así se lo permiten. La prevención y el control del SIDA debería ser una prioridad para el IPSS.

En 1990, el Dr. Jonathan Mann, ex Director del Programa Mundial del SIDA de la Organización Mundial de Salud, dijo que América Latina estaba a tiempo de evitar una epidemia de SIDA; en 1992 el Dr. Mann en el estudio "AIDS in the World" hecho en la escuela de Salud Pública de la Universidad e Harvard, demostró que en América Latina el Perú era uno de los tres países con alta vulnerabilidad para desarrollar una epidemia de SIDA.

Desde el Programa Nacional de SIDA luego de desarrollar una estrategia educativa dirigida a los medios de comunicación masiva, logramos aumentar el nivel de información de la población de Lima de un 10 a 20\% en 1989 hasta 82\% a finales de 1991.

Hemos dado el primer paso, la población de Lima está más informada acerca del Sida (¿qué es, cómo se contagia, cómo se previene?), ahora falta lo más difícil, lograr que esta población modifique sus comportamientos de riesgo y/o adopte comportamientos sexuales saludables.

No tenemos tiempo que perder, debemos tener conciencia de que la única forma de enfrentar el SIDA es librándonos de perjuicios sociales y religiosos, empecemos a hablar abierta y seriamente sobre nuestra sexualidad y la forma de practicarla saludablemente, promocionando 
la monogamia, la disminución de parejas, el uso adecuado del condón y diagnosticando y tratando las enfermedades de transmisión sexual.

No podemos seguir jugando con la salud de tantos peruanos, tampoco debemos permitir que la incapacidad destruya lo que está hecho, es hora que todas las instituciones y personas capaces de aportar algo a esta lucha lo hagan sin egoísmo pues está en juego el futuro de nuestros hijos y por ende del Perú.

\section{REFERENCIAS BIBLIOGRÁFICAS}

1.Amor y sexualidad en los tiempos del Sida: Los jóvenes de Lima Metropolitana. Programa Especial de Control del Sida. Ministerio de Salud del Perú. Julio 1991.

2.Costo directo del Sida. Recursos presentes y futuros requeridos en México. AIDSTECH. 1988.

3.AIDS 91 Summary. A practical Sypnosis of the VII Internacional Conference. Junio 16-21. 1991. Florencia.

4.Reunión de Directores de Programas Nacionales de Sida. Organización Panamericana de la Salud. Washington. Noviembre 1990.

5.Estadísticas del Programa Nacional de Control del Sida. Ministerio de Salud del Perú. Abril 1993.

6.Boletín Informativo. Año 1/N²/Set. 1991. Programa Especial de Control del Sida. Ministerio de Salud del Perú. Mujer y Sida.

7.Socio Economics aspects of HIV and AIDS in developing countries London School of Higiene and Tropical Medicine. Department of Public Health and Policy. 1991.

8.Sexo seguro en la era del Sida para hombres y mujeres. Instituto para el estudio avanzado de la sexualidad humana. Editorial Universo. México. 1987.

9.Ferrando, Delicia. Los jóvenes en el Perú. Opiniones, actitudes y valores. Cedro. 1987.

10.Todos por la Salud. guía de Comunicación para la Vida. UNICEF. 1989. 